\title{
Saldo de radiação em cafeeiros e limeiras: Relações com saldo de radiação de gramado e radiação global
}

\author{
Jones Simon ${ }^{1} \&$ Luiz R. Angelocci ${ }^{2}$ \\ ${ }^{1}$ Embrapa Pesca e Aquicultura, Palmas, TO. E-mail: jones.simon@embrapa.br (Autor correspondente) \\ ${ }^{2}$ Depto. de Engenharia de Biossistemas/ESALQ/USP, Piracicaba, SP. E-mail: Irangelo@usp.br
}

Palavras-chave:

saldo de radiação

pomar

citros

cafezal

\begin{abstract}
R E S U M O
O balanço de radiação da copa das árvores (Rnc) é uma das principais variáveis de interesse em estudos hídricos e de crescimento de culturas de espécies lenhosas, mas sua determinação direta é tarefa difícil e limitada a trabalhos experimentais. O uso da técnica de varredura da copa por radiômetros com integração espaço-temporal da absorção pela folhagem permite testar modelos de estimativa e estabelecer relações entre Rnc e variáveis meteorológicas, como saldo de radiação de gramado (Rng) e radiação solar global ( $\mathrm{Rg})$. A técnica de varredura foi usada em um trecho de renque de pomar de limeira ácida e de cafezal, em Piracicaba, SP, tendo-se verificado bons ajustes por equações lineares e polinomiais quadráticas, para a relação de Rnc com Rng e com Rg nas várias estações do ano para o cafezal, em dados integrados a cada 15 min e na escala horária e para a estação de inverno no pomar; entretanto, o ajuste não foi bom para o verão. Para valores integrados no período diurno ocorreram bons ajustes nas duas culturas, em todos os períodos estudados.
\end{abstract}

Key words: net radiation orchard citrus coffee

\section{Radiation balance in coffee and lime plants: Relationships with grass net and solar radiations}

\begin{abstract}
A B S T R A C T
The all-wave radiant energy absorbed by the canopy (Rnc) of trees is one of the main variables of interest in water studies and crop growth of woody species, but its direct determination is not an easy task, being limited to experimental work. Scanning the top of trees along plant hedgerows by moving net radiometers around them is a technique that renders possible spatiotemporal integration of Rnc values, allowing the tests of physico-mathematical models and establishing of correlations of Rnc with routine measurements of incoming solar radiation $(\mathrm{Rg})$ and grass net radiation (Rng). Integrated values measured by this technique in a stretch of rows of a coffee plantation and an acid lime orchard were correlated with Rng and Rg. For the coffee crop, linear and quadratic polynomial equations fitted well for the relationship of Rnc with Rg and Rng for autumn, winter and spring in 15 min, hourly and diurnal time-scales, but for the summer only in the diurnal scale this occurred. For the lime orchard, good fits were obtained in the three timescales in the winter, but only for the diurnal timescale in the summer.
\end{abstract}

\section{INTRODUÇÃO}

A energia radiante absorvida pela copa das espécies lenhosas é de interesse em vários campos de pesquisa básica e aplicada ao crescimento vegetal, às relações hídricas e trocas gasosas, mas a determinação da variação espaço-temporal dessa absorção não é tarefa fácil (Samani et al., 2007), estando restrita a poucos trabalhos.

Thorpe (1978) utilizou oito saldo-radiômetros tubulares fixos a distâncias equilatitudinais de $45^{\circ}$ em torno da copa de uma macieira em renque, tendo o maior eixo do sensor $(0,9$ $\mathrm{m}$ ) orientado paralelamente a linha de plantio e a placa sensora direcionada perpendicularmente ao raio da copa, formando um cilindro nocional com o comprimento igual ao das placas, permitindo amostragem espaço-temporal e estimativa do saldo de radiação da copa. Com o mesmo intuito, Angelocci et al.
(2008) empregaram saldo-radiômetros pontuais se deslocando em torno das copas no sentido da linha de plantio de cafezal e em pomar de limeira ácida com a vantagem de amostrar um trecho de renque com várias árvores e não somente parte de uma planta.

O desenvolvimento dessas técnicas representa o aperfeiçoamento da metodologia de determinação da interação da energia radiante com dosséis vegetativos descontínuos ou em renques porém as dificuldades impostas ao seu uso fazem com que fiquem restritas a trabalhos de pesquisa. Uma alternativa é o desenvolvimento de modelos físico-matemáticos de absorção de radiação pela copa (Campbell, 1986; Riou et al., 1989; Marin, 2003; Green et al., 2003; Annadale et al., 2004; Oyarzun et al., 2007). Outra é o estabelecimento de relações de Rnc com a irradiância solar global $(\mathrm{Rg})$ ou com o saldo de radiação de gramado (Rng) (Angelocci et al., 2004; Pilau et al., 2007; 
Heldwein et al., 2012) procedimento mais simples do que o uso de modelagem, ainda que haja restrição à transferabilidade dos resultados para outras condições de cultivo. Em qualquer hipótese, a técnica de varredura se mostra útil por permitir o estabelecimento das relações citadas e para o teste de modelos.

Neste trabalho são apresentadas e discutidas as relações entre Rnc de trechos de renque de cafezal e de pomar de limeiras (pela técnica de varredura em várias épocas do ano), o saldo de radiação medido sobre gramado e, a irradiância solar global em diferentes escalas.

\section{Material e Métodos}

O trabalho foi desenvolvido em um cafezal ( 3,2 ha) e em um pomar de limeiras ácidas (1,0 ha) localizados no Campus "Luiz de Queiroz", Universidade de São Paulo Piracicaba, SP $\left(22^{\circ} 42^{\prime} \mathrm{S} ; 47^{\circ} 30^{\prime} \mathrm{W}\right.$, alt. $546 \mathrm{~m} \mathrm{e}, 22^{\circ} 42^{\prime} \mathrm{S}$; $47^{\circ} 38^{\prime} \mathrm{W}$, alt. $511 \mathrm{~m}$, respectivamente).

O cafezal, implantado em outubro de 2001, era composto por plantas em pé franco de Coffea arabica cv. Obatã IAC $1669-20 \mathrm{em}$ linhas de plantio com orientação NW-SE (azimute de $152^{\circ} 56^{\prime}$ ), espaçamento de $3,5 \times 0,9 \mathrm{~m}$, formando renques com altura média de 2,0 m e largura de 1,7 m. O pomar de limeira ácida [Citrus latifolia (Yu.Tanaka) Tanaka cv. IAC 5] foi implantado em 2001, com espaçamento de 7,0 x 4,0 m, orientados no sentido E-W (azimute de $91^{\circ} 07^{\prime}$ ), com largura média de 5,60 $\mathrm{m}$ e altura média de $4,5 \mathrm{~m}$. As medidas foram realizadas em 60 dias entre março 2008 e fevereiro 2009 no cafezal e em 7 dias de dezembro de 2008 e 11 dias em junho de 2009 no pomar, períodos esses em que foi possível obter medidas contínuas o dia todo sem problemas de funcionamento do instrumental ou de ocorrência de chuva.

A área foliar foi determinada por dois procedimentos, um baseado na coleta e contagem de todas as folhas das plantas analisadas e outro utilizando-se medidor portátil de IAF (LAI2000 Canopy Analyser, Li-Cor, Lincoln, NE, USA). No cafezal foram feitas determinações uma vez em cada estação do ano, sendo somente na última determinação utilizado o medidor portátil, junto com as medidas em folhas. Neste último caso foi utilizada uma árvore fora do renque em estudo, representativa das condições médias do cafezal. No pomar foram realizadas duas determinações, a primeira com o LI-2000 durante as medidas e a segunda com coleta e contagem de folhas logo após o final do experimento. Simultaneamente foi determinada a porosidade média da folhagem tomando-se fotos digitais das paredes laterais e da superior do trecho de renque tendo, como contraste, um grande lençol branco para homogeneizar o plano de fundo das imagens as quais foram analisadas no programa Quant2000 (Universidade Federal de Viçosa), permitindo a quantificação da área livre de folhas e a estimativa da porosidade do renque.

Com vista à determinação do saldo de radiação das copas dos cafeeiros foi utilizado um sistema integrador já utilizado neste cafezal (Pilau, 2005; Angelocci et al., 2008) e nas limeiras criou-se um sistema semelhante (Simon, 2010). Funcionavam com deslocamento, no sentido da linha de plantio, constituído de um arco circular metálico no qual foram fixados saldoradiômetros Q 7.1 (REBS, Logan, Utah) distribuídos em torno da folhagem, em posições equilatitudinais $\left(45^{\circ}\right.$ no cafezal e $30^{\circ}$ no pomar), com suas placas sensoras tangenciando a superfície hipotética do cilindro nocional (cafezal: radiômetros de 1 a 4 instalados na face NW e os de 5 a 8 na SE. Pomar: radiômetros 1 a 6 voltados para as faces $\mathrm{S}$ e 7 a 12 para a N). O arco circular foi movimentado sobre trilhos fixados ao solo, pelo uso de uma (cafezal) e duas (pomar) correntes metálicas tracionadas por engrenagem redutora de velocidade, acoplada a motor elétrico de $1 \mathrm{HP}$. O trajeto percorrido pelos sensores foi de 4,7 $\mathrm{m}$ (5 plantas) e $16,0 \mathrm{~m}$ (4 plantas), no cafezal e no pomar, respectivamente. A inversão do movimento nos trilhos ocorria automaticamente quando o arco atingia uma das extremidades do percurso, por um mecanismo mecânico de reversão. Maiores detalhes dos sistemas são encontrados em Marin (2003), Pilau (2005), Angelocci et al. (2008) e Simon (2010).

Como cada sensor amostrava os fluxos de entrada e de saída das radiações de ondas curtas e longas e se considerandose positivos as entradas e negativas as saídas, a equação de integração é:

$$
\mathrm{Rnc}=\left(\frac{1}{\mathrm{n}} \sum_{\mathrm{i}=\mathrm{n}}^{\mathrm{n}} \mathrm{Rn}_{\mathrm{i}}\right) \mathrm{d}_{\mathrm{h}} \cdot 2 \cdot \mathrm{R} \cdot \pi
$$

sendo:

Rnc - saldo de radiação das copas integrado no tempo e na distância (dh) percorrida pelos sensores na linha de plantio

$\mathrm{n} \quad$ - número de sensores

Rni - saldo de radiação de cada saldo-radiômetro

$\mathrm{R}$ - raio da base do cilindro nocional

Dois dataloggers foram acoplados aos sistemas, um modelo CR1000 e outro CR10 (Campbell Scientific Inc.) para aquisição, integração e armazenamento de valores médios de Rnc em intervalos de $15 \mathrm{~min}$. Os dados de irradiância solar global (Rg) e saldo de radiação de gramado (Rng) foram obtidos por piranômetro CM3 e saldo-radiômetro (Kipp \& Zonen B.V.), respectivamente instalados na estação meteorológica do Campus Luiz de Queiroz.

\section{Resultados E Discussão}

Na Tabela 1 são fornecidos os valores médios de área foliar (AF), índice de área foliar (IAF) e porosidade média (P\%) da copa no sentido vertical. No outono (maio/2008) ocorreu o maior valor de AF no cafezal, consequência da boa disponibilidade hídrica no solo nos meses de verão e início do outono. Posteriormente, ocorreu a diminuição de AF, pelo efeito de ocorrência de déficit hídrico, além de enfraquecimento vegetativo pós-colheita, sendo o menor valor atingido na primavera (outubro/2008). Os meses posteriores foram de baixa pluviosidade principalmente novembro, mas ocorreu pequena recuperação da área foliar em fevereiro/2009. No pomar de limeiras houve diminuição de cerca de $20 \%$ da área foliar no inverno, pela senescência de folhas velhas.

Foram obtidas relações por análise de regressão com os valores integrados das variáveis em três escalas de tempo: 
Tabela 1. Área foliar média por árvore (AF), índice de área foliar (IAF) e porosidade média do dossel (P\%) para cafezal e limeiras ácidas

\begin{tabular}{lccccccc}
\hline & \multicolumn{4}{c}{ Cafezal } & & \multicolumn{2}{c}{ Limeiras ácidas } \\
\cline { 2 - 5 } \cline { 7 - 7 } & Outono & Inverno & Primavera & Verão & & Verão & Inverno \\
$\mathrm{AF}\left(\mathrm{m}^{2}\right)$ & 14,7 & 11,8 & 9,0 & 9,5 & & 58,0 & 50,0 \\
$\mathrm{IAF}$ & 9,0 & 7,5 & 5,9 & 6,4 & 3,1 & 2,5 \\
$\mathrm{P}(\%)$ & 7,2 & 9,0 & 11,8 & 11,2 & & 10,5 & 11,4 \\
\hline
\end{tabular}

* IAF determinado por unidade de área de solo na projeção das copas
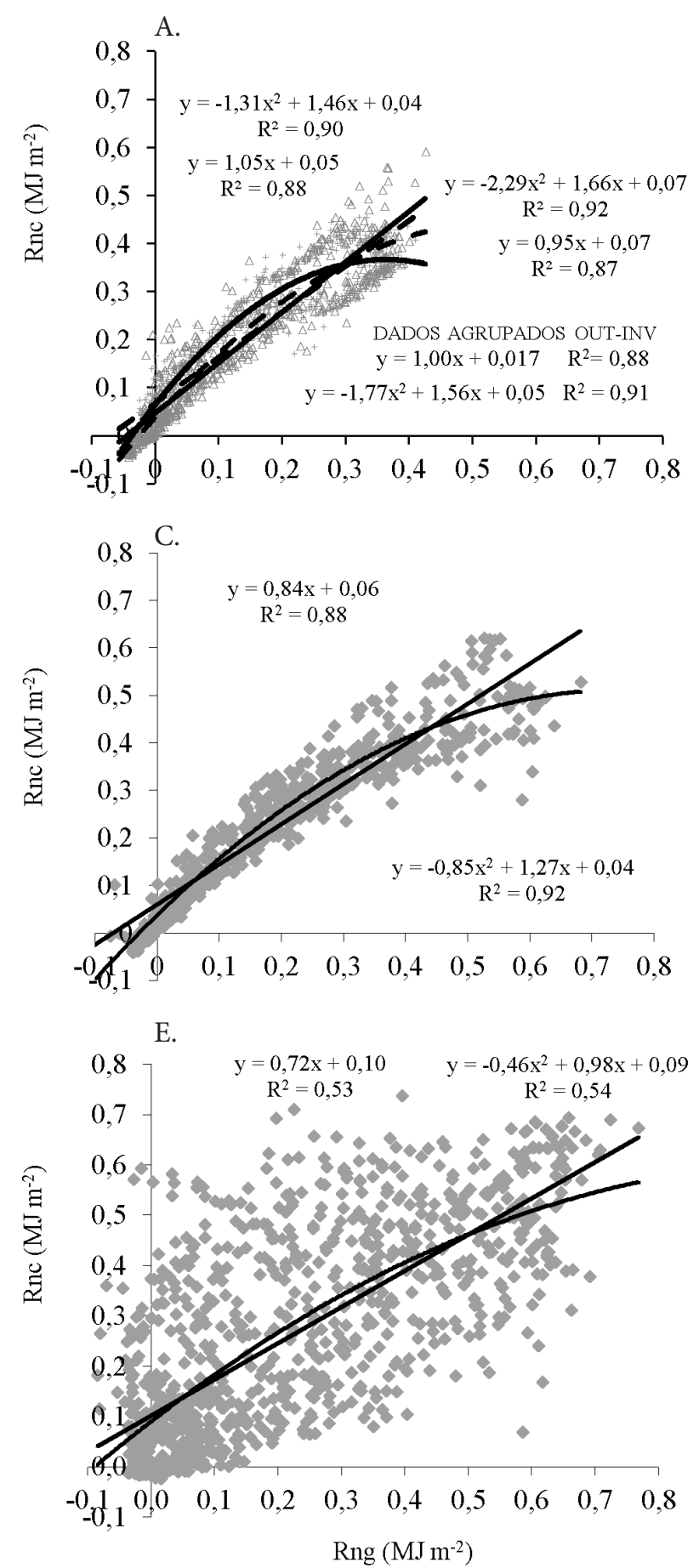

15 min, horária e período diurno. Com base em trabalhos anteriores obtidos em cafezais no Campus Luiz de Queiroz (Marin, 2003; Pilau, 2005; Angelocci et al., 2008), foram testados ajustes polinomiais de primeira e segunda ordem, empregandose, como variável dependente, o saldo de radiação por unidade de área da copa projetada verticalmente sobre o terreno (Rnc). Foram ajustadas equações para cada período de estudo. $\mathrm{Na}$ Figura 1, encontram-se os resultados do cafezal na escala de
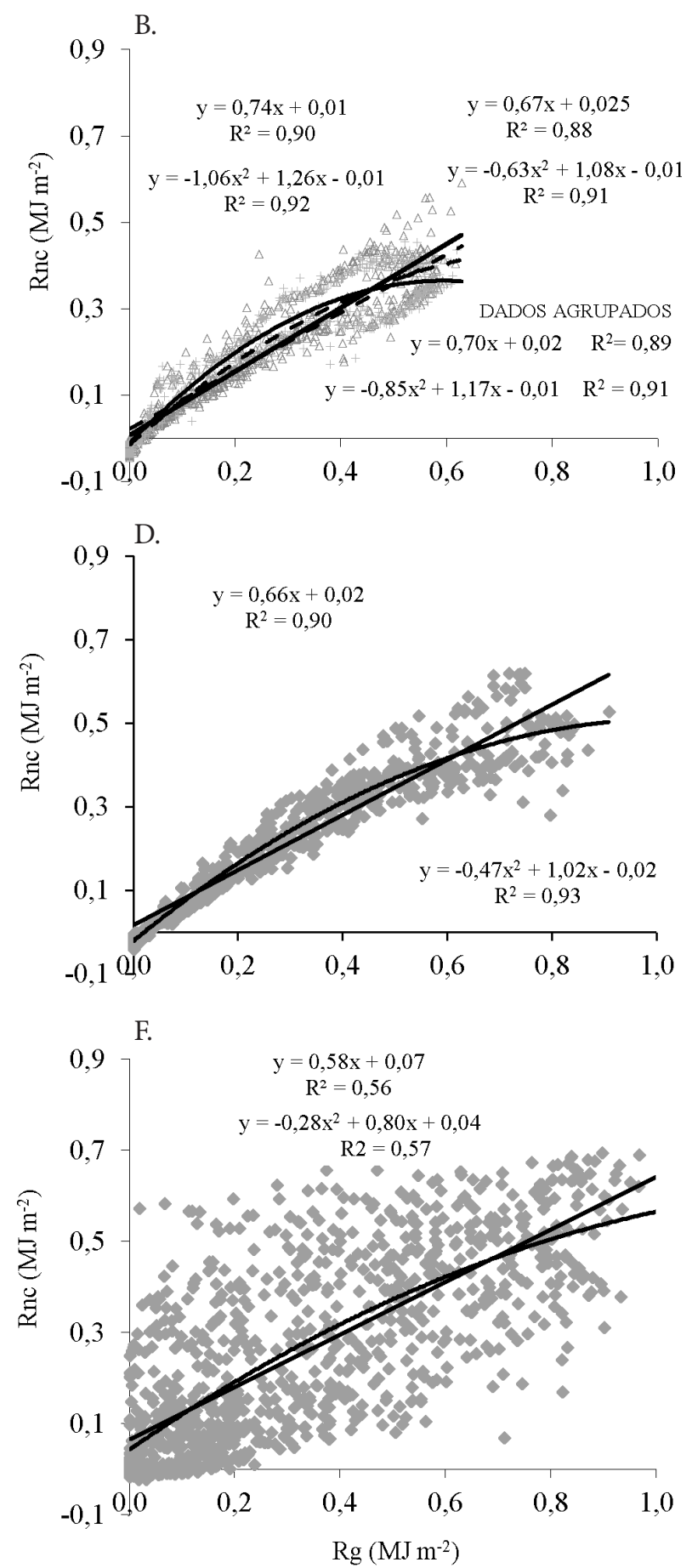

Figura 1. Relações lineares e polinomiais e valores de $R^{2}$, para valores integrados de $15 \mathrm{~min}$, do saldo de radiação das copas de cafeeiros por unidade de área projetada verticalmente sobre o terreno (Rnc) com o saldo de radiação de gramado (Rng) e radiação solar global (Rg) para outono e inverno 2008 (A,B, sendo linhas cheias para outono e tracejadas para inverno), primavera $(C, D)$ e verão $(E, F)$ 
15 min; para o verão a dispersão dos dados é elevada (com $\mathrm{R}^{2}$ variando entre 0,53 e 0,57 , indicando baixa correlação), enquanto nas outras estações ela foi pequena. Observa-se o efeito da variação de $\mathrm{AF}$ e de $\mathrm{P} \%$ sobre as relações, atestado pela diminuição dos coeficientes das equações lineares para cada estação, em correspondência à diminuição temporal de IAF e aumento de P\% (Tabela 1). Ajustaram-se equações representativas englobando o conjunto de dados do outono e
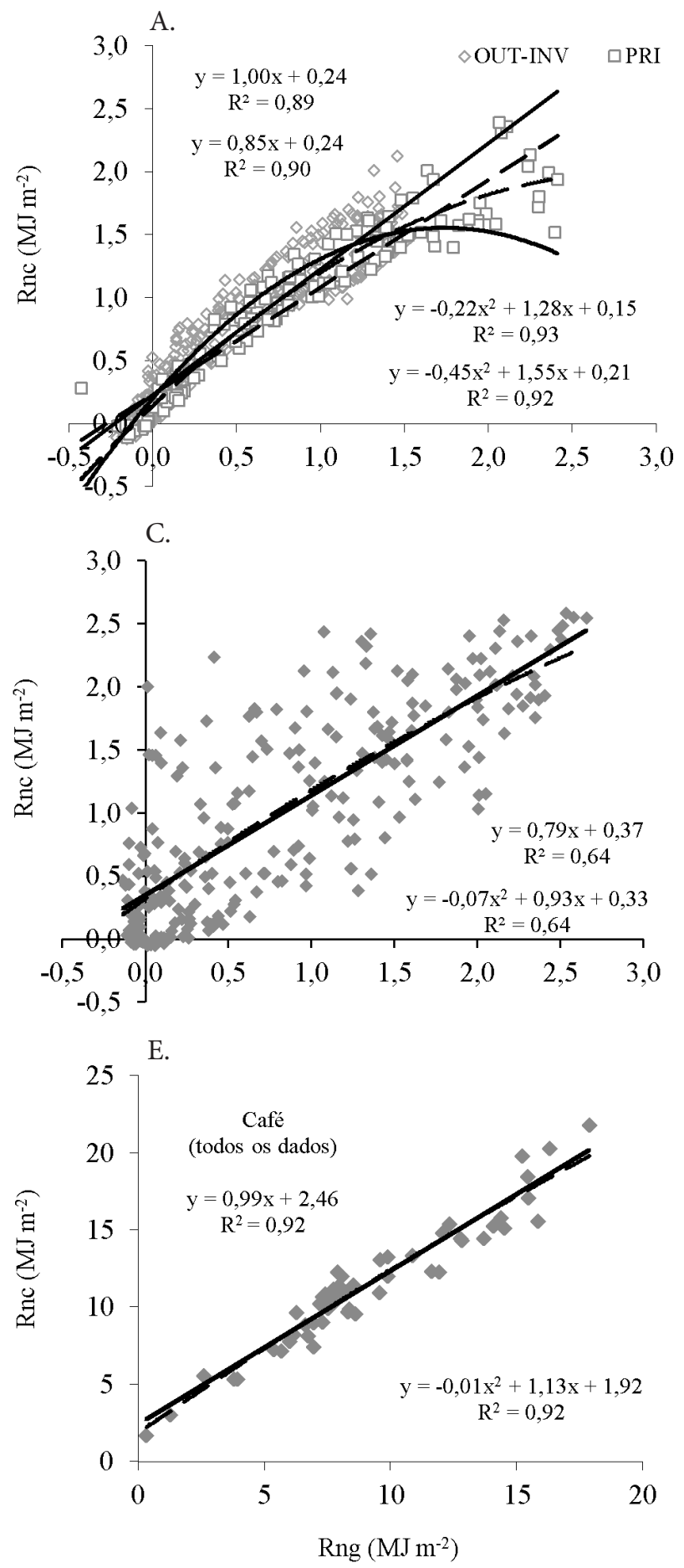

inverno, sendo que os resultados obtidos para o agrupamento de dados das duas estações (Figuras 1A e 1B) indicam que se pode usar a equação de agrupamento no lugar das referentes a cada estação, com altos valores de $\mathrm{R}^{2}$ para todas as equações obtidas, com exceção do período do verão (Figuras 1E e 1F) em que a dispersão dos dados aumenta.

Elevadas correlações foram observadas para os valores integrados nas escalas horária e diurna (Figura 2), no outono,
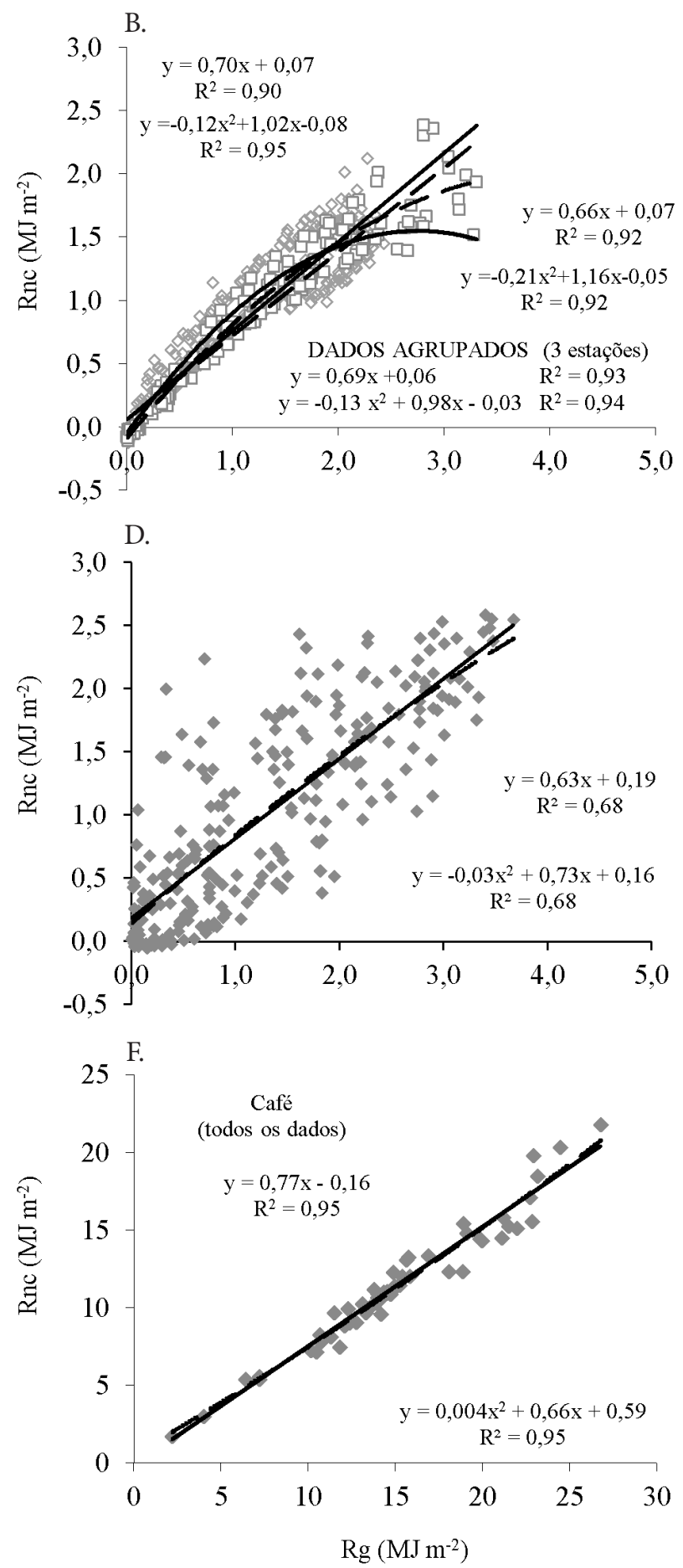

Figura 2. Relações do saldo de radiação das copas de cafeeiros por unidade de área foliar projetada verticalmente sobre o solo (Rnc) com o saldo de radiação de gramado (Rng) e radiação solar global (Rg) com valores integrados para a escala horária para outono, inverno e primavera de 2008 (A,B) e para o verão (C,D); para o período diurno foram usados todos os dados agrupados $(\mathrm{E}, \mathrm{F})$, independente do período do ano 
inverno e primavera, com altos valores de $\mathrm{R}^{2}$ e com bons ajustes entre Rnc e Rg nas três estações, nos dados integrados por hora (campo superior à direita da Figura 2), com valores de $\mathrm{R}^{2}$ de 0,93 e 0,94 para o ajuste de primeiro e segundo graus, respectivamente; para uma análise mais detalhada nesta mesma escala, são mostrados valores agrupados para outono e inverno.

Para o verão os valores de $\mathrm{R}^{2}$ nessas duas escalas temporais (horária e diurna) também aumentaram em relação os de 15

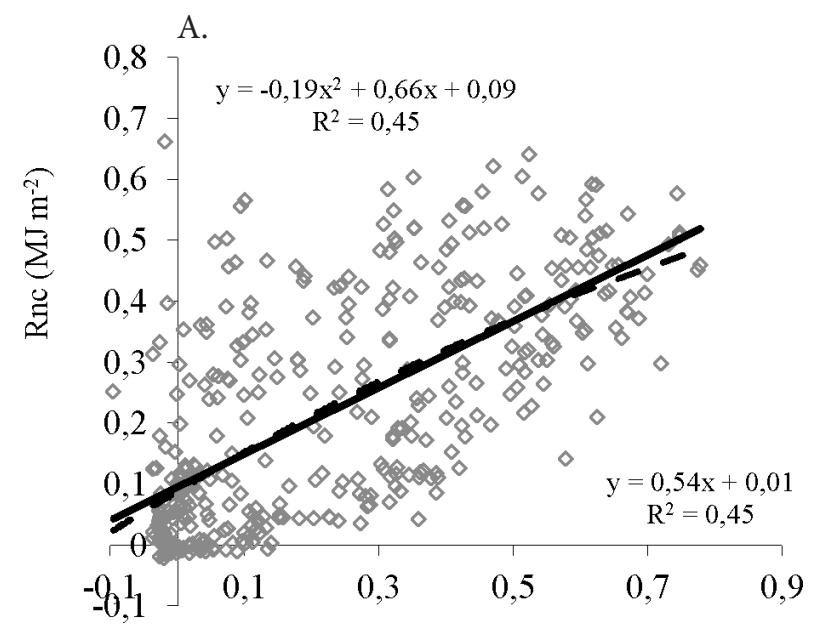

C.
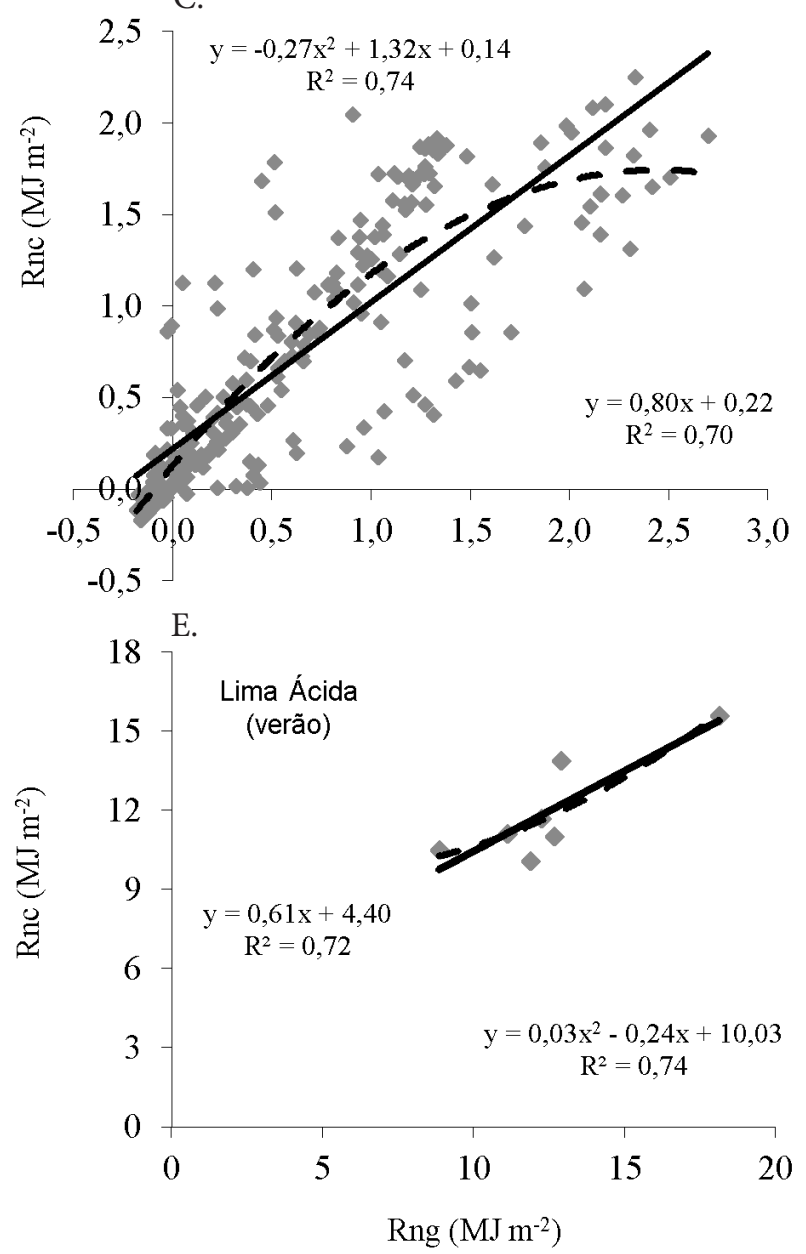

min mas não o suficiente para diminuir a dispersão e melhorar a representatividade das equações. Entretanto, é possível verificar que, independente da estação do ano, os ajustes na escala diurna apresentaram pequena dispersão o que permitiu o estabelecimento de equações com excelentes ajustes para o conjunto de valores agrupados (campo inferior da Figura 2) o que pode ser consequência de compensação de valores ocorridos nos períodos da manhã e da tarde como se discutirá

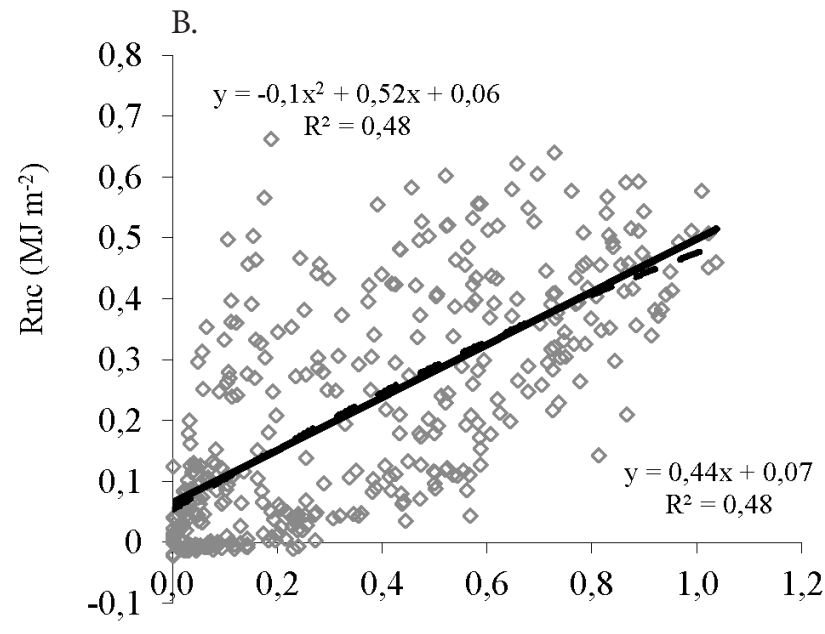

D.
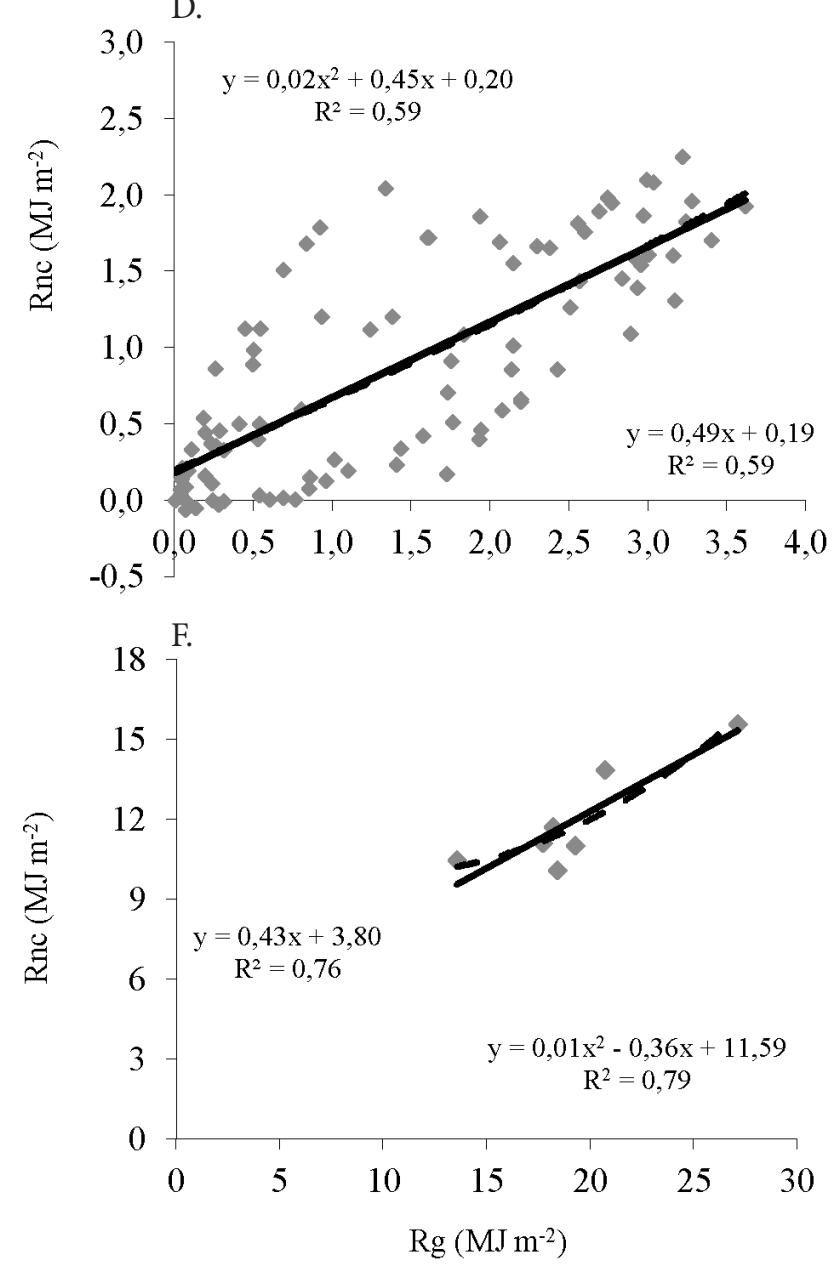

Figura 3. Relações do saldo de radiação das copas de lima ácida por unidade de área projetada verticalmente sobre o solo (Rnc) com o saldo de radiação de gramado (Rng) $(A, C, E)$ e radiação solar global $(R g)(B, D, F)$ no verão (dezembro de 2008) nos períodos de $15 \mathrm{~min}$, hora e diurno, respectivamente 
adiante. Observa-se também que na escala diurna praticamente não há diferenças entre os ajustes polinomiais de primeiro ou segundo graus.

Também se observam, para o pomar de limeiras, as baixas correlações no verão (Figura 3) principalmente nas escalas de 15 min e horária enquanto que na escala diurna os valores de $\mathrm{R}^{2}$ são mais elevados ( 0,72 para $\mathrm{Rng}$ e 0,75 para $\left.\mathrm{Rg}\right)$, o que se deve ao fato de o número de pares de valores ser pequeno nessa
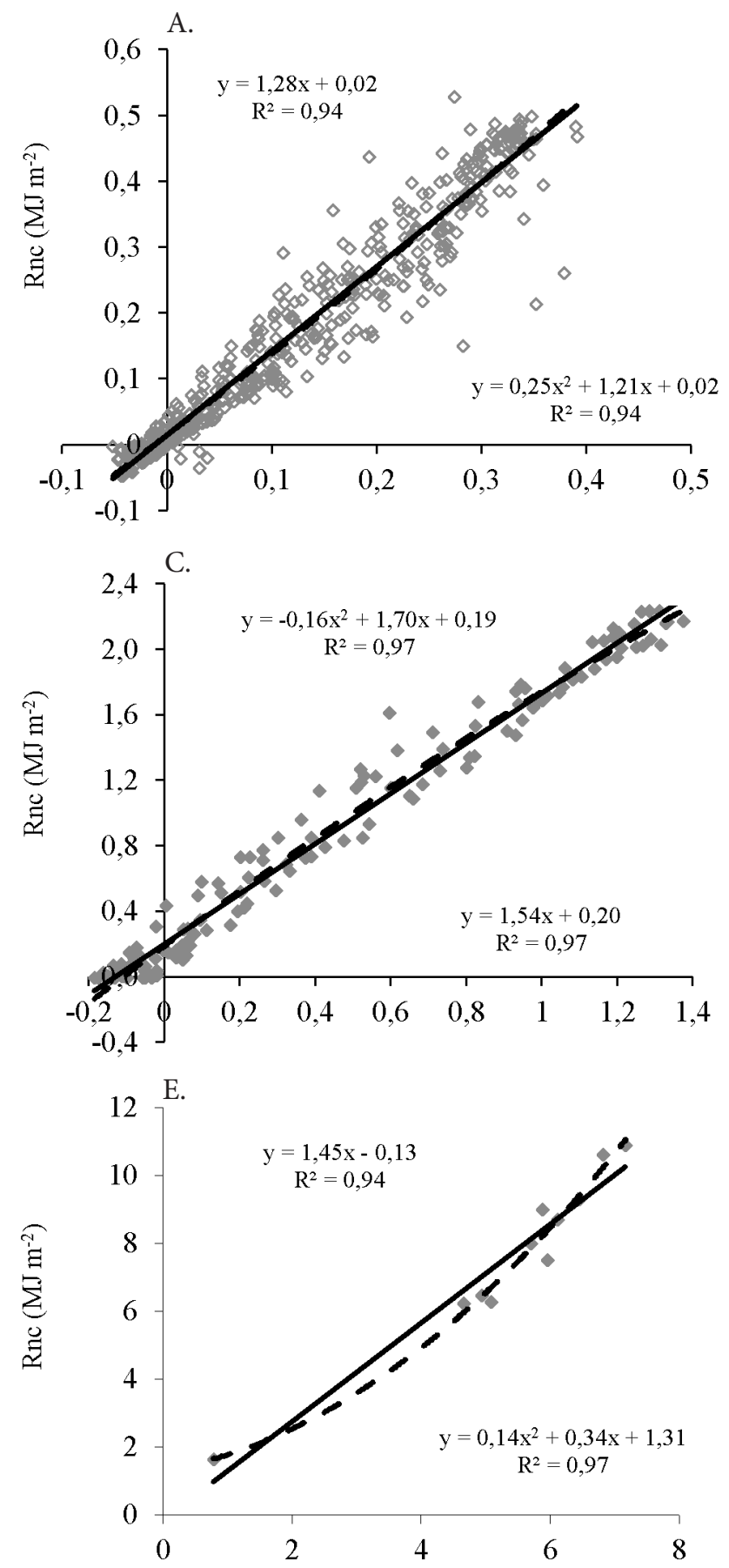

Rng (MJ m-2) escala de tempo de integração. Por outro lado se observam excelentes correlações nas três escalas de tempo para o inverno (Figura 4), com valores de $\mathrm{R}^{2}$ acima de 0,94 e praticamente não ocorrendo diferenças entre os ajustes polinomiais de primeiro ou segundo graus, em qualquer escala. Interessante é observar que para esta estação os coeficientes das equações lineares se diferenciam entre as duas culturas, sendo maiores para o pomar, mesmo tendo este apresentado uma porosidade de copas $26 \%$
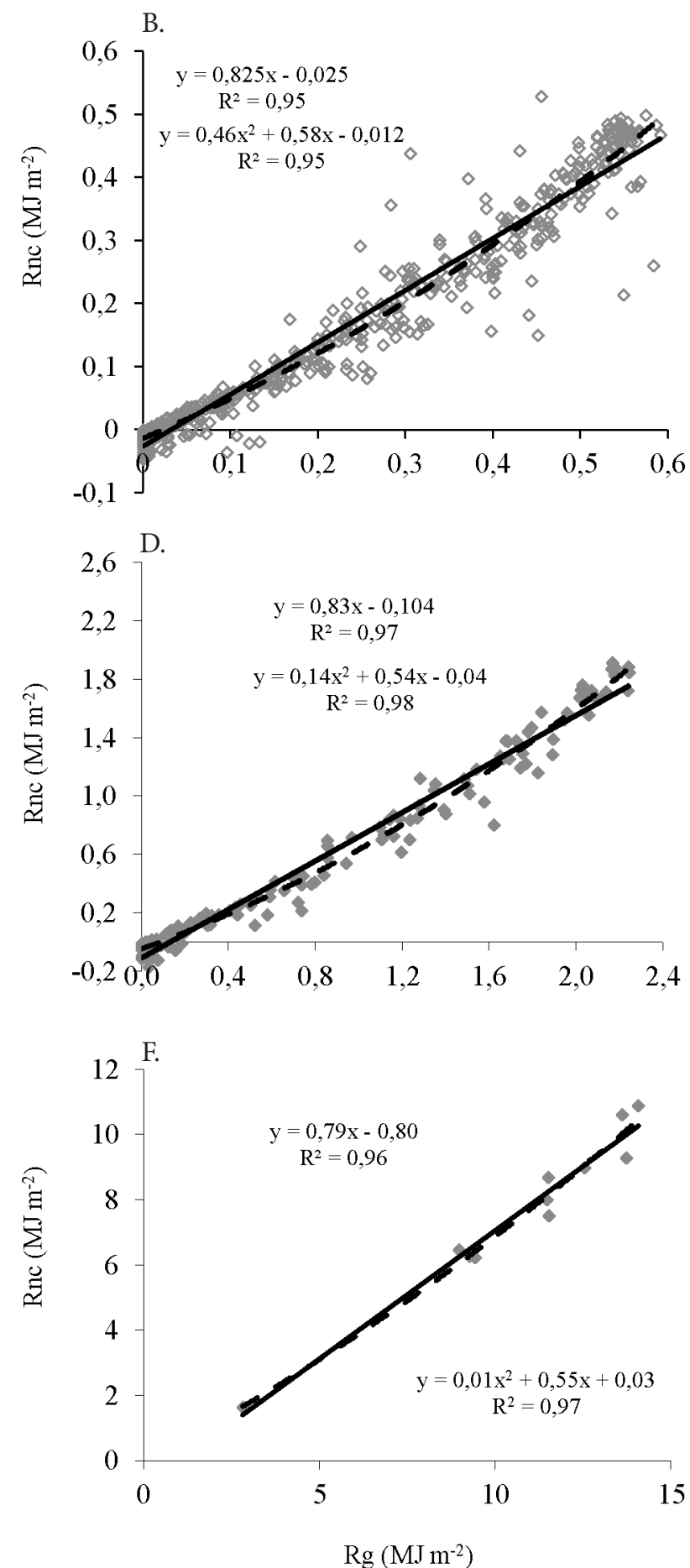

Figura 4. Relações do saldo de radiação das copas de lima ácida por unidade de área foliar projetada verticalmente sobre o solo (Rnc) com o saldo de radiação de gramado (Rng) e radiação solar global (Rg) com valores integrados nos períodos de $15 \mathrm{~min}(\mathrm{~A}, \mathrm{~B})$, horário $(\mathrm{C}, \mathrm{D})$ e diurno $(\mathrm{E}, \mathrm{F})$, considerando-se os dados obtidos no inverno de 2009 
maior e IAF cerca de 3 vezes menor do que o cafezal. Embora isto possa ser indicativo de problemas na medida de IAF e P\%, também pode ser consequência da diferença de orientação dos renques entre as culturas.

Uma explicação para a baixa correlação no verão é encontrada quando se plotam os dados de Rnc, Rng e Rg integrados em $15 \mathrm{~min}$ ao longo do período diurno em vários dias para cada cultuta (Figuras 5 e 6). Para melhor entendimento,

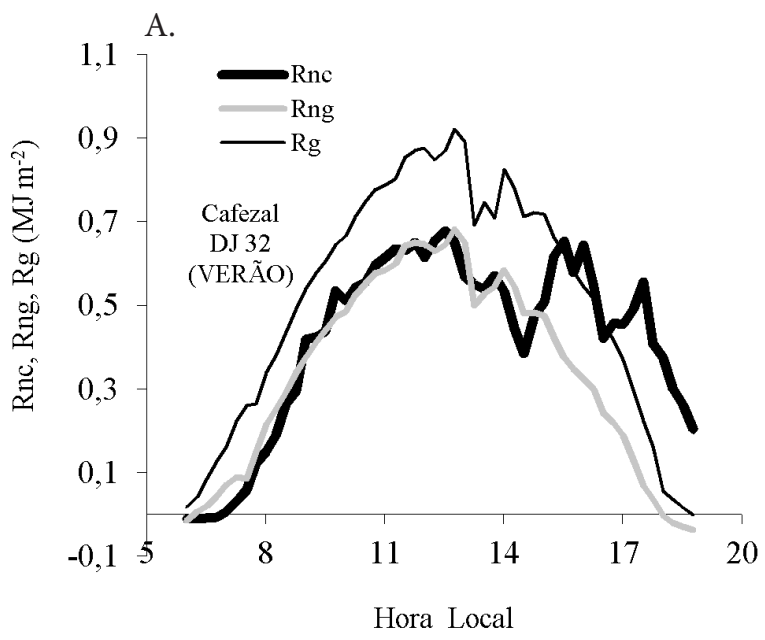

C.

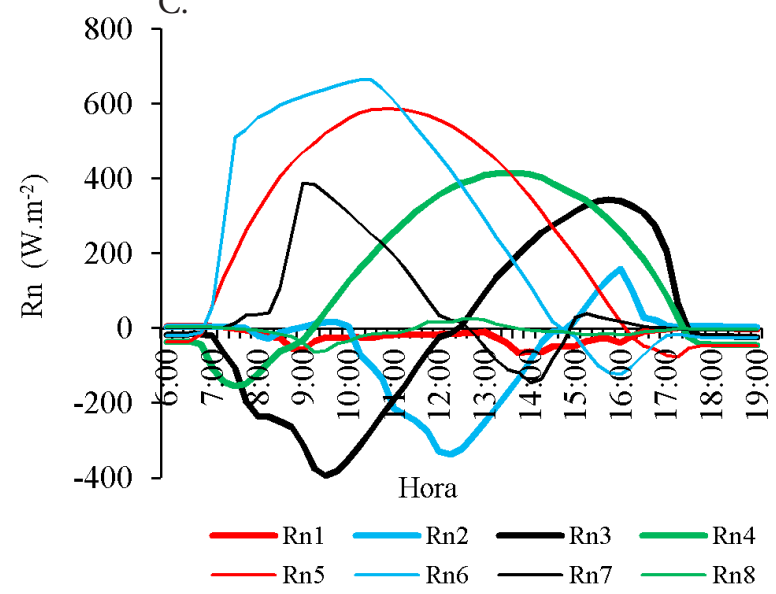

E.

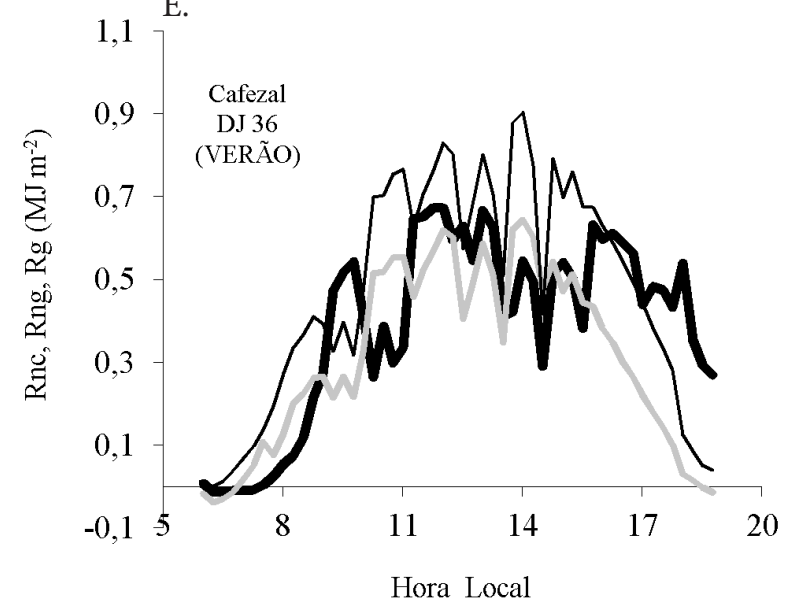

dois dias em cada cultura são plotados com os valores obtidos via saldo-radiômetros, identificando a contribuição da medida de cada um ao valor de Rnc.

No cafezal, em dia pouco nublado de verão (DJ 32) os valores tendem a se alinhar com aqueles de $\mathrm{Rg}$ em toda a manhã e no início da tarde sendo que a partir de cerca de $15 \mathrm{~h}$ Rnc aumenta e ultrapassa Rg. Este padrão é consequência do efeito da orientação SE-NW do renque sobre a interceptação
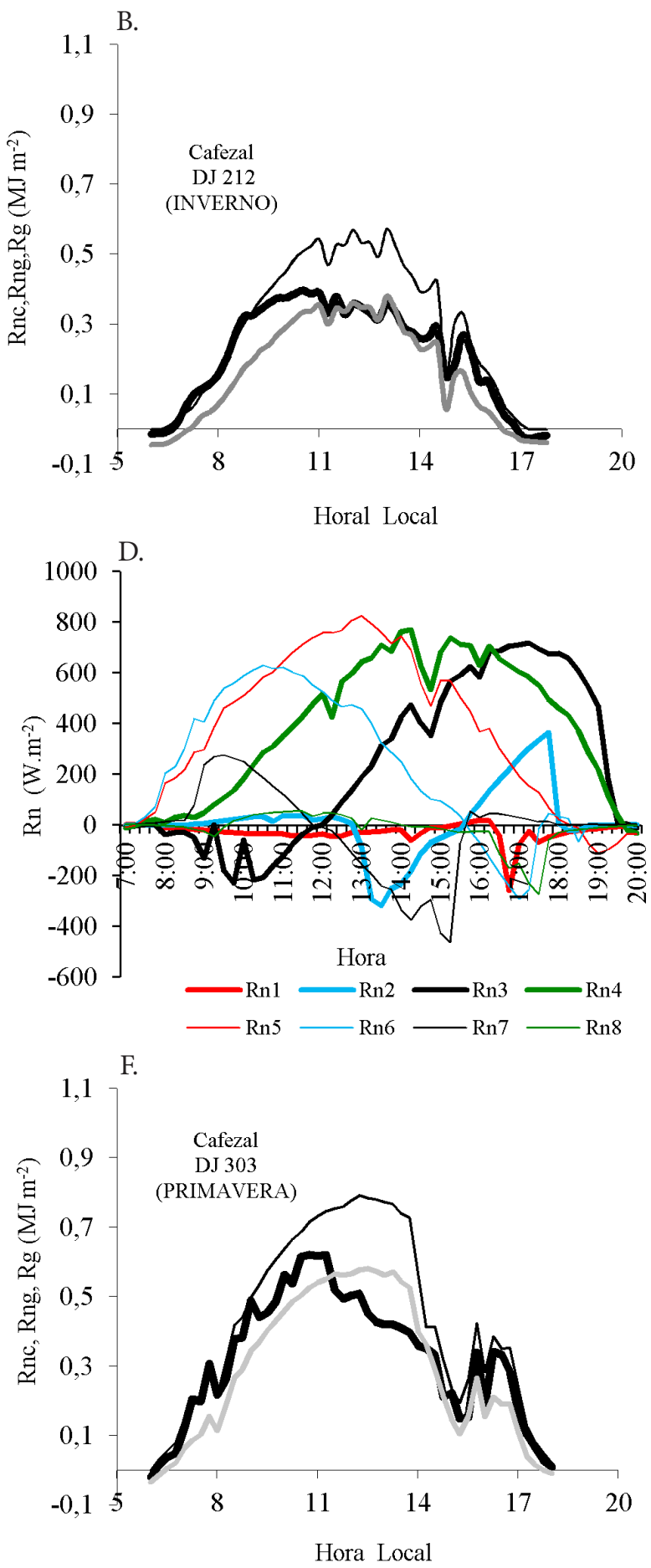

Figura 5. Variação dos dados integrados em 15 min do saldo de radiação das copas do cafeeiro (Rnc), saldo de radiação do gramado (Rng) e da radiação solar global (Rg), em dias no verão (A,E), inverno (B) e primavera (F); as curvas em cores indicam a variação da medida do saldo de radiação das copas para cada um dos oito saldo-radiômetros (Rn1,.... Rn8) instalados em torno das copas, no dia de verão (D) e no de inverno (C) 
de radiação solar, com sua face voltada para SE (radiômetros 5 a 8) irradiada diretamente de manhã e à tarde com a voltada para noroeste (sensores 1 a 4). Os estratos que mais contribuem para o valor de Rnc são os referentes às posições varridas por Rn3, Rn4, Rn5 e Rn6, na parte superior da copa. Os sensores Rn3 e Rn4 contribuem para o aumento de Rnc na tarde fazendo com que ele se torne maior do que o próprio Rg; para o DJ 212 (inverno), os valores de Rnc acompanham os de $\mathrm{Rg}$ no início da
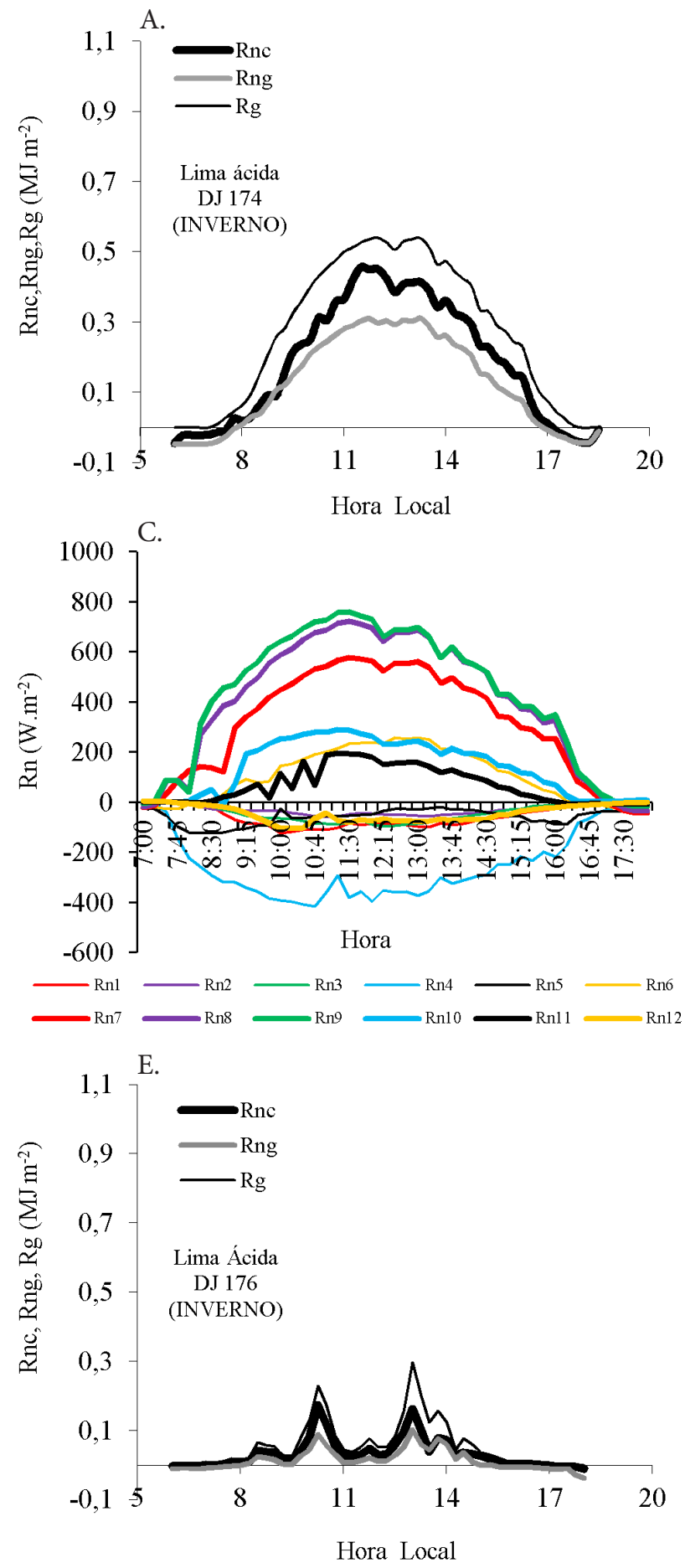

manhã, depois se tornam relativamente estáveis e se aproximam de Rng entre 11 e $14 \mathrm{~h}$, para mais tarde acompanhar os valores de Rg. Padrões análogos de assimetria dos valores de Rnc entre períodos correspondentes da manhã e tarde para o verão e de simetria para a primavera, são observados em dias nublados (DJ 36 e DJ 303) com maiores oscilações no verão.

Para o pomar de limeiras (Figura 6) observa-se que, ao longo do período diurno, no inverno, os valores de Rnc se mantêm
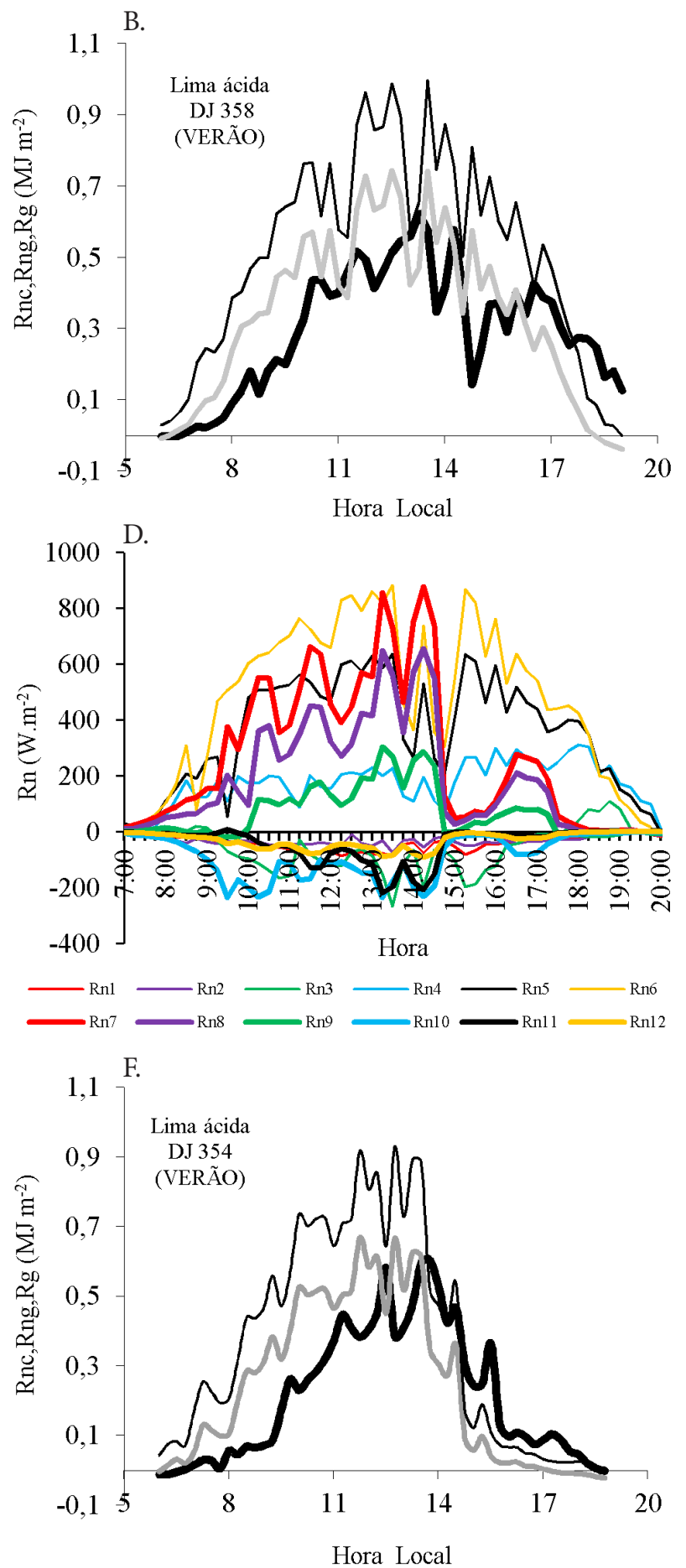

Figura 6. Variação dos dados integrados em 15 min no período diurno da irradiação solar global (Rg), do saldo de radiação de gramado (Rng) e do saldo de radiação das copas de lima ácida (Rnc) em dois dias do ano no inverno $(A, E)$ e dois dias no verão $(B, F)$; as curvas em cores representam a variação da medida em cada saldo-radiômetro no inverno e no verão, respectivamente $(C, D)$ 
intermediários entre Rg e Rng, ainda que nas primeiras horas da manhã e no período final da tarde se aproximem de Rng. Mesmo em um dia nublado (DJ 176) este padrão de valores intermediários ocorre. Para o verão observa-se que os valores de Rnc são inferiores a Rng e Rg em toda a manhã tendendo a se aproximar de Rng no meio do dia, para depois ultrapassar Rng e Rg, este último do meio para o final da tarde em ambos os dias mostrados, bastante nublados. Como a orientação da linha de plantio é praticamente E-W, os padrões de variação de saldo de radiação em cada estrato das copas (figuras em cores) são diferentes daqueles do cafezal. No pomar há tendência de Rnc acompanhar temporalmente Rg e Rng mas os dados dos radiômetros denotados de 6 a 11 contribuem com valores positivos e os demais com negativos, sendo os do primeiro grupo de magnitude absoluta maior. Para o dia de verão (DJ 358) os valores que mais contribuem são os medidos por Rn4 até Rn9.

Os padrões nas Figuras 5 e 6 explicam a grande dispersão no verão na escala de tempo de $15 \mathrm{~min}$ pois as relações de Rnc com Rng e Rg não se mantêm iguais na manhã nem na tarde, ou seja, para um mesmo valor de Rnc, Rng e Rg tomam valores diferentes de acordo com o período do dia, mesmo para dia de céu límpido. Além disto, nebulosidade variável ao longo do dia, frequente para o verão, favorece o aumento da dispersão de vez que a composição atmosférica altera a relação entre as radiações solar direta e difusa em diferentes graus, por se refletir na escala horária, enquanto que na escala diurna a ocorrência de compensação nas diferenças horárias promove diminuição da dispersão. Os resultados obtidos permitem concluir ser possível estabelecer boas correlações entre o saldo de radiação das copas de árvores em renques com o saldo de radiação de gramado (Rng) e irradiância solar global (Rg), nas três escalas de tempo adotadas mas no verão a boa correlação somente é observada com os valores integrados na escala diurna. As equações quadráticas geralmente se revelaram de melhor ajuste que as lineares, mas na grande maioria dos casos as diferenças entre os dois tipos de ajuste foram pouco significativas nos meses de outono, inverno e primavera. Esses resultados explicam as boas relações obtidas em um cafezal, variedade Mundo Novo, com 5 anos de implantação plantado no mesmo local e, neste experimento quando este tinha 3 anos de implantação (Marin, 2003; Pilau, 2005; Angelocci et al., 2008). Nesses trabalhos a dispersão dos dados foi pequena mas não foram realizadas medidas no verão.

Deve-se atentar para o fato de que as equações apresentadas aqui são de utilização válida sob condições de crescimento (índice área foliar, porosidade e geometria da copa) e orientação dos renques próximas daquelas ocorrentes no presente estudo.

Neste estudo os valores médios das razões entre Rnc e Rng para o cafezal se apresentam superiores aos obtidos por Pilau (2005) no mesmo cafezal aqui utilizado, mas quando tinha somente 3 anos de implantação e IAF entre 3 a 4 vezes menor. São também superiores aos encontrados por Pezzopane et al. (2005), em cafezal a pleno sol. Para limeira somente foram encontradas, na literatura, relações com as mesmas variáveis aqui estudadas obtidas por Pilau et al. (2007), para árvore isolada.

\section{Conchusões}

1. Foi possível estabelecer equações bem ajustadas entre o saldo de radiação da copa de cafeeiros e limeiras $(\mathrm{Rnc})$ em renques e o saldo de radiação de gramado (Rng), bem como com a radiação solar global (Rg), nas escalas de integração de 15 min, horária e diurna nas várias estações do ano, excetuando-se o período de verão no qual se obtiveram bons ajustes somente na escala diurna.

2. A grande dispersão dos dados decorrente dos padrões temporais de absorção de radiação nos diferentes estratos das copas das duas culturas, não permitiu um bom ajuste de Rnc com Rng e com Rg no verão.

3. As relações encontradas são específicas e não podem ser transferidas para condições de crescimento e de geometria de plantio diferentes das observadas para este cafezal e pomar de limeira ácida.

\section{Literatura Citada}

Angelocci, L. R.; Marin, F. R.; Pilau, F. G.; Righi, E. Z.; Favarin, J. L. Radiation balance of coffee hedgerows. Revista Brasileira de Engenharia Agrícola e Ambiental, v.12, p.274-281, 2008.

Angelocci, L. R.; Villa-Nova, N. A.; Coelho Filho, M. A.; Marin, F. R. Measurements of net radiation absorbed by isolated acid lime trees (Citrus latifolia Tanaka). The Journal of Horticultural Science and Biotechnology, v.79, p.699-703, 2004.

Annandale, J. G.; Jovanovic, N. Z.; Campbell, G. S.; Du Santoy, N.; Lobit, P. Two-dimensional solar radiation interception model for hedgerow fruit trees. Agricultural and Forest Meteorology, v.121, p.207-225, 2004.

Campbell, G. S. Extinction coefficients for radiation in plant canopies calculated using an ellipsoidal inclination angle distribution. Agricultural and Forest Meteorology, v.36, p.317-321, 1986.

Green, S.; McNaughton, K.; Wünsche, J. N.; Clothier, B. Modeling light interception and transpiration of apple tree canopies. Agronomy Journal, v.95, p.1380-1387, 2003.

Heldwein, A. B.; Maldaner, I. C.; Bosco, L. C.; Trentin, G.; Grimm, E. L.; Radons, Z. R.; Lucas, D. D. P. Saldo de radiação diurno em dosséis de batata como função da radiação solar global. Revista Ciência Agronômica, v.43, p.96-104, 2012.

Marin, F. R. Evapotranspiração e transpiração máxima em cafezal adensado. Piracicaba: ESALQ/USP, 2003. 134p. Tese Doutorado

Oyarzun, R. A.; Stockle, C. O.; Whiting, M. D. A simple approach to modeling radiation interception by fruit tree orchards. Agricultural and Forest Meteorology, v.142, p.1224, 2007.

Pezzopane, J. R. M.; Pedro, M. J.; Gallo, P. B. Radiação solar e saldo de radiação em cultivo de café a pleno sol e consorciado com banana "Prata Anã". Bragantia, v.64, p.485-497, 2005. 
Pilau, F. G. Saldo de radiação da copa de laranjeira num pomar e de renques de cafeeiros: medidas e estimativas. Piracicaba: ESALQ/USP, 2005. 92p. Tese Doutorado

Pilau, F. G.; Angelocci, L. R.; Scarpari, J. A. Radiation balance of an orange tree in orchard and its relation with global solar radiation and grass net radiation. Revista Brasileira de Agrometeorologia, v.15, p.257-266, 2007.

Riou, C.; Valancogne, C. ; Pieri, P. Un modèle simple d'interception du rayonnement solaire par la vigne - Vérification expérimentale. Agronomie, v.9, p.441-450, 1989.
Samani, Z.; Bawazir, A. S.; Bleiweiss, M.; Skaggs, R.; Tran, V. $D$. Estimating daily net radiation over vegetation canopy through remote sensing and climatic data. Journal of Irrigation and Drainage Engineering, v.133, p.291-297, 2007.

Simon, J. Medições do saldo de radiação em copas de cafeeiros e limeiras ácidas por sistemas de integração espaço-temporal e estimativas por técnicas de modelagem. Piracicaba: ESALQ/ USP, 2010. 112p. Tese Doutorado

Thorpe, M. R. Net radiation and transpiration of apple trees in rows. Agricultural and Forest Meteorology, v.19, p.41-57, 1978. 